\title{
Increasing of malignancy of breast cancer cells after cryopreservation: molecular detection and activation of angiogenesis after CAM-xenotransplantation
}

Xinxin Du ${ }^{1,2}$, Plamen Todorov ${ }^{3}$, Evgenia Isachenko ${ }^{1}$, Gohar Rahimi ${ }^{1}$, Peter Mallmann ${ }^{1}$, Yuanguang Meng ${ }^{2}$ and Vladimir Isachenko ${ }^{1 *}$ (D)

\begin{abstract}
Background: Ovarian tissue cryopreservation has a wide range of cancerous indications. Avoiding relapse becomes a specific concern that clinicians frequently encounter. The data about the comparative viability of cancer cells after cryopreservation are limited. This study aimed to evaluate the effect of cryopreservation on breast cancer cells.

Methods: We used in-vitro cultured ZR-75-1 and MDA-MB-231 cell lines. Cell samples of each lineage were distributed into the non-intervened and cryopreserved groups. The cryopreservation procedures comprised programmed slow freezing followed by thawing at $100^{\circ} \mathrm{C}, 60 \mathrm{~s}$. Biological phenotypes and the related protein markers were compared between the two groups. The EVOS FL Auto 2 Cell Image System was used to monitor cell morphology. Cell proliferation, motility, and penetration were characterized by CCK-8, wound-healing, and transmembrane assay, respectively. The expression of Ki-67, P53, GATA3, E-cadherin, Vimentin, and F-Actin was captured by immunofluorescent staining and western blotting as the proxy measurements of the related properties. The chorioallantoic membrane (CAM) xenotransplantation was conducted to explore angiogenesis induced by cancer cells.

Results: After 5 days in vitro culture, the cell concentration of cryopreserved and non-intervened groups was 15.7 $\times 10^{4}$ vs. $14.4 \times 10^{4} \mathrm{cell} / \mathrm{s} / \mathrm{ml}$, (ZR-75-1, $\left.p>0.05\right)$, and $25.1 \times 10^{4}$ vs. $26.6 \times 10^{4}$ cells $/ \mathrm{ml}(\mathrm{MDA}-\mathrm{MB}-231, p>0.05)$. Some cryopreserved ZR-75-1 cells presented spindle shape with filopodia and lamellipodia and dissociated from the cell cluster after cryopreservation. Both cell lines demonstrated increased cell migrating capability and invasion after cryopreservation. The expression of Ki-67 and P53 did not differ between the cryopreserved and non-intervened groups. E-cadherin and GATA3 expression downregulated in the cryopreserved ZR-75-1 cells. Vimentin and F-actin exhibited an upregulated level in cryopreserved ZR-75-1 and MDA-MB-231 cells. The cryopreserved MDA-MB-231 cells induced significant angiogenesis around the grafts on CAM with the vascular density $0.313 \pm 0.03$ and $0.342 \pm$ 0.04 , compared with that of non-intervened cells of $0.238 \pm 0.05$ and $0.244 \pm 0.03, p<0.0001$.

(Continued on next page)
\end{abstract}

\footnotetext{
*Correspondence: vladimir.isachenko@gmail.com

'Research Group for Reproductive Medicine, IVF-Laboratory and Department of Gynecology, University of Cologne, Kerpener str. 34, 50931 Cologne, NRW, Germany

Full list of author information is available at the end of the article
}

C C The Author(s). 2020 Open Access This article is licensed under a Creative Commons Attribution 4.0 International License, which permits use, sharing, adaptation, distribution and reproduction in any medium or format, as long as you give appropriate credit to the original author(s) and the source, provide a link to the Creative Commons licence, and indicate if changes were made. The images or other third party material in this article are included in the article's Creative Commons licence, unless indicated otherwise in a credit line to the material. If material is not included in the article's Creative Commons licence and your intended use is not permitted by statutory regulation or exceeds the permitted use, you will need to obtain permission directly from the copyright holder. To view a copy of this licence, visit http://creativecommons.org/licenses/by/4.0/ The Creative Commons Public Domain Dedication waiver (http://creativecommons.org/publicdomain/zero/1.0/) applies to the data made available in this article, unless otherwise stated in a credit line to the data. 
(Continued from previous page)

Conclusions: Cryopreservation promotes breast cancer cells in terms of epithelial-mesenchymal transition and angiogenesis induction, thus increasing metastasis risk.

Keywords: Cryopreservation, Breast cancer, Epithelial-mesenchymal transition, Metastasis, Angiogenesis, Chorioallantoic membrane

\section{Background}

With the aim of fertility preservation, ovarian tissue cryopreservation (OTC) is currently the medical treatment of an increasing application [1]. The beneficiaries include the prepubertal, adolescent, and young adults diagnosed with malignant diseases e.g. gastrointestinal carcinoma, leukemia and breast cancer [1,2]. Clinicians concern about the existence of disseminated cancer cells that are dormant in the ovaries before anti-cancer treatment [3]. However, data about effect of cryopreservation on viability of cancer cells are limited.

As reported, cryopreservation adversely affected the decidualization potential and cytokine production of human endometrial stromal cells [4]. The activity of xenobiotic metabolizing enzymes and responsiveness to enzyme-inducing agents reduced in cryopreserved human hepatocytes compared with that in freshly isolated cells [5]. However, cryopreserved umbilical cord blood mononuclear cells (UCB-MNCs) exhibit similar properties to those of fresh UCB in vitro and in vivo [6]. Endothelial progenitor cells derived from UCB-MNCs induced responses to cytokines and recovery of carotid artery injury analogous with those from peripheral blood of healthy volunteers [7].

Optimization of procedures of cryopreservation has an aim to improve the viability of post-thawing cells [8-10]. Concurrently, the vitality of veiled or dormant cancer cells should not be neglected. Concealed disseminated cancer cells are asymptomatic and are thought to be growth-arrested in G0 to G1 of cell cycle and thus in a quiescent state during the freezing process. These cells evade the immune response and are untreatable due to drug resistance [11].

This study aimed to evaluate the effect of cryopreservation on human breast cancer cells in the form of compacted fragments (as a model of solid tumors).

\section{Methods}

\section{Cell lines and culture}

Except where otherwise specified, all reagents were obtained from Sigma (Sigma Chemical Co., St. Louis, USA).

ZR-75-1 and MDA-MB-231 cell lines were purchased from American Type Culture Collection (Manassas, USA, ATCC ${ }^{\circ}$ Numbers: CRL-1500 ${ }^{\mathrm{mm}}$; HTB-26 $6^{\mathrm{m}}$, respectively). The cell lines were tested for mycoplasma contamination before being performed in this study using
LookOut Mycoplasma PCR Detection Kit (Sigma-Aldrich, St. Louis, MO). Cells were in vitro cultured in AIM V Medium (Thermo Fisher Scientific, Waltham, USA) supplemented with $10 \%$ fetal bovine serum (FBS) and Amphotericin $\mathrm{B}$ at $37^{\circ} \mathrm{C}$ in a humidified chamber with $5 \% \mathrm{CO}_{2}$. Culture media were renewed every $48 \mathrm{~h}$.

The process of using breast cancer cell monolayer to form the model tissue of a solid tumor was previously described [12]. Briefly, the in-vitro cultured cells after three times of cell passages were maintained in the culture medium for 10 days without cell passage. Culture medium was renewed every $24 \mathrm{~h}$ after a cell monolayer was formed. A cell scraper (Greiner Bio-one, Frickenhausen, Germany) was used to harvest and accumulate the cell layer as the model tissue for the followed cryopreservation. This method was also manipulated to collect the cancer cells for the chorioallantoic membrane (CAM) xenotransplantation and in vivo culture.

Cell samples of each lineage were distributed into the non-intervened and cryopreserved groups.

\section{Cryopreservation (freezing and thawing) of the model tissues}

Cryopreservation of compacted fragments of cancer cells was implemented based on the protocols for cryopreservation of human ovarian tissue [13] with modifications and peculiarities as described below. The model tissues were frozen and thawed subjected to the process for ovarian strips.

The harvested tissues were kept for 5 min (ZR-75-1 cells) and $10 \mathrm{~min}$ (MDA-MB-231 cells) in the standard 5 $\mathrm{ml}$ cryo-vials (Thermo Fisher Scientific, Rochester, USA) previously filled by $4.5 \mathrm{ml}$ freezing solutions (medium L15 supplemented with $6 \%$ dimethyl sulfoxide, $6 \%$ ethylene glycol and $0.15 \mathrm{M}$ sucrose) and precooled at $4{ }^{\circ} \mathrm{C}$. Then the tissues were frozen using the IceCube 14S freezer (SyLab, Neupurkersdorf, Austria). The slow cooling profile started at $-6^{\circ} \mathrm{C}$ with auto-seeding. The samples were then cooled from -6 to $-34{ }^{\circ} \mathrm{C}$ at a rate of $-0.3^{\circ} \mathrm{C} / \mathrm{min}$. At $34^{\circ} \mathrm{C}$, the cryovials were plunged into liquid nitrogen and stored until thawing.

For the thawing of samples, the cryo-vial was removed from liquid nitrogen and held for $30 \mathrm{~s}$ at room temperature, then immersed in a $100^{\circ} \mathrm{C}$ (boiling) water bath for $60 \mathrm{~s}$. The exposure time in the boiling water was visually controlled by the presence of ice in the 
medium. Then the cryo-vial was removed from the boiling water when the ice was in the form of $1-2 \mathrm{~mm}$ apex, and the final temperature of the medium was between 4 and $10{ }^{\circ} \mathrm{C}$. After $90 \%$ freezing medium was discarded within 10 s, the cryo-vial was filled by $37^{\circ} \mathrm{C}$ pre-warmed thawing solution (basal medium containing $0.5 \mathrm{M}$ sucrose) and put into thermostat at $37^{\circ} \mathrm{C}$ for $7 \mathrm{~min}$ and 15 min for ZR-75-1 and MDA-MB-231 cells, respectively, to remove the intracellular cryoprotectants. Then, approximately $90 \%$ thawing medium in the vial was expelled. The basal (culture) medium was slowly added into the vial holding the residual solution and the tissue inside, using the 'dropping' methodology for the stepwise rehydration [14]. The final concentration of sucrose was $0.05 \mathrm{M}$, resulting in an isotonic condition. After rehydration, the tissue fragments were digested by $6 \mathrm{ml} 0.05 \%$ Trypsin-EDTA and maintained in the incubator for 5 $\mathrm{min}$ at $37^{\circ} \mathrm{C}, 5 \% \mathrm{CO}_{2}$. After washing and centrifugation, the cell pellet was resuspended in $10 \mathrm{ml}$ culture medium by fully pipetting and then transferred into a $10 \mathrm{~cm}$ cell culture dish to allow adhesion overnight.

\section{Observation of cell proliferation and morphology}

The non-intervened and cryopreserved group of cells were seeded at a concentration of $1 \times 10^{4}$ cells $/ \mathrm{ml}$ in 96 well plates and allowed to adhere overnight. Cell proliferation was measured using Cell Counting Kit-8 (CCK8 ) and observed consecutively for 5 days. From day 1 to 5 , ten $\mu$ l CCK- 8 solution was added to each well of one plate at a fixed time and incubated for $4 \mathrm{~h}$, then the OD at $450 \mathrm{~nm}$ (reference $650 \mathrm{~nm}$ ) was determined by a multimode reader machine (Tecan Group Ltd., Maennedorf, Zurich, Switzerland). Culture medium was renewed every $48 \mathrm{~h}$. Results were plotted to draw a cell-growing curve with the time axis as the abscissa and the cell count as the vertical axis. Each experiment was repeated three times. For the morphology change, cells were maintained in the $10 \mathrm{~cm}$ culture dish to observe under microscopy each day. Images were taken by EVOS FL Auto 2 Cell Imaging System (Thermo Fisher Scientific).

\section{Assessment of cell motility and invasion}

Cell migration and invasion were determined using the wound-healing and 3D transwell assay. The woundhealing assay was implemented with a well-established artificial gap on the confluent cell monolayer. A density of $1 \times 10^{6}$ cells $/ \mathrm{ml}$ in $140 \mu \mathrm{l}$ suspension of both cell lines was seeded in a $35 \mathrm{~mm} \mu$-Dish ibidi Culture Insert (ibidi $\mathrm{GmbH}$, Planegg, Bavaria, Germany) with $70 \mu \mathrm{l}$ in each well, incubated for $24 \mathrm{~h}$ and obtained the cell layers. After removal of the insert, the $\mu$-Dish was washed with PBS twice to remove cell debris and non-attached cells and filled with $2 \mathrm{ml}$ of $1 \%$ FBS-supplemented cell-free medium. Time-lapse measurement of the wound area between the cell layers was conducted at time points 24 , 48, and $72 \mathrm{~h}$ for ZR-75-1 and 2, 4, and $6 \mathrm{~h}$ for MDAMB-231 cells to calculate cell front velocity. Experiments were carried out in triplicate at least three times.

Corning transwell inserts were used to accomplish the cell migration and invasion assay, according to our previous study [12]. Polycarbonate filters $(6.5 \mathrm{~mm}$ in diameter, $8 \mu \mathrm{m}$ pore size) were coated with type I rat tail collagen $(100 \mu \mathrm{g} / \mathrm{ml}$, BD Biosciences, Franklin Lakes, USA) for $1 \mathrm{~h}$ at $37^{\circ} \mathrm{C}$ by the manufacturer's protocol. The non-intervened and cryopreserved cells were resuspended and seeded into the upper compartment of the insert in the serum-free culture medium, respectively. ZR-75- 1 cells were seeded at $2 \times 10^{5}$ cells/well and cultured for $72 \mathrm{~h}$; MDA-MB-231 cells were seeded $5 \times 10^{4}$ cells/well and cultured for $8 \mathrm{~h}$. The lower chamber was filled with $600 \mu \mathrm{l}$ of the appropriate culture medium supplemented with FBS as a chemoattractant. After incubation, the upper insert with cells was washed with PBS, fixed with $4 \%$ formaldehyde, and permeabilized with methanol at room temperature. Cells were then stained with $0.1 \%$ crystal violet solution and were gently rinsed with PBS and wiped by cotton-tipped swabs then dried in the air. Penetrative cells went through the polymerized collagen layer to the bottom of the polycarbonate membranes and were counted in five different fields of view under a microscope. For the migration assay, cells were treated using the same procedure, except that the transwell membrane was not coated with collagen. Samples in each group ran in triplicate. Each experiment was performed at least three times.

\section{Immunofluorescent (IF) staining}

Antibodies were purchased from Biolegend. Twentyfive $\times 10^{4}$ cells were first seeded on cover glasses in 6well plates. After $48 \mathrm{~h}$, the culture medium was aspirated, and cells were fixed with $2 \%$ paraformaldehyde for $20 \mathrm{~min}$ at room temperature. After washing twice by PBS, the cells were incubated in $0.5 \%$ Triton X-100 in PBS for $10 \mathrm{~min}$ for permeabilization and blocked by cell staining buffer (Biolegend, San Diego, USA) for $30 \mathrm{~min}$. Then the coverslips were transferred into a humidified chamber and incubated with Alexa Fluor 488-conjugated anti-human Ki-67 antibody, Alexa Fluor 594 anti-human Epithelial cadherin (E-cadherin) antibody, Alexa Fluor 647 anti-GATA3 antibody and Alexa Fluor 488 antiVimentin antibody overnight at $4{ }^{\circ} \mathrm{C}$, or with Alexa Fluor 488-conjugated Flash Phalloidin (F-Actin) in room temperature for $1 \mathrm{~h}$. After washing twice, the coverslips were mounted on glass slides with $25 \mu$ of mounting medium with 4',6-diamidino-2-phenylindole (Abcam, Cambridge, UK). The slides were analyzed by a Leica SP8 confocal microscope. Images were taken using LAS X software (Leica Microsystems, Wetzlar, Germany). 


\section{Western blotting (WB)}

Cultured cells were incubated in Accutase at $37^{\circ} \mathrm{C}$ for 5-10 min, followed by resuspension and centrifugation. Cell lysis was conducted using lysis buffer: RIPA buffer (Thermo Fisher Scientific) with protease inhibitor cocktail. Cell lysates were separated by centrifuging at 20000 g, $30 \mathrm{~min}$ at $4{ }^{\circ} \mathrm{C}$. Protein concentrations were measured via Bradford test and adjusted to $20 \mu \mathrm{g} / 20 \mu \mathrm{l}$ in one sample by $4 \mathrm{X}$ sodium dodecyl sulfate-containing laemmli sample buffer, then heated in boiling water for $5 \mathrm{~min}$. Later, sodium dodecyl sulfate-polyacrylamide gel electrophoresis (SDS-PAGE) was applied to separate the total protein, and then separated protein was transferred on nitrocellulose membrane. We used the pre-cast $4-12 \%$ polyacrylamide gradient gels (Thermo Fisher Scientific) and the Trans-Blot ${ }^{\circ}$ Turbo $^{\text {Tm }}$ membrane (Biorad, Hercules, USA) in the transfer system according to the manufacturer instruction. After blocking, the membrane was incubated in primary antibodies diluted to 1:2000 by $5 \%$ Bovine Serum Albumin in PBST $(0.1 \%$ Tween-20 in PBS) at $4{ }^{\circ} \mathrm{C}$ overnight. The P53, E-cadherin, GATA3, and Vimentin antibodies were purchased from Cell Signaling Technologies (Danvers, Massachusetts, USA). The following day, the fluorescent secondary antibodies (LI-COR, Lincoln, NE, USA) were used to incubate at room temperature for $2 \mathrm{~h}$. Bands were visualized using Odyssey Clx (LI-COR). Image J software (http://developer.imagej.net) was used to estimate the band density.

\section{CAM-xenotransplantation: induction of angiogenesis and tumor growth}

Preparation of the chick embryo chorioallantoic membrane (CAM) for transplantation of cancer cells were performed as described early $[15,16]$. Briefly, fertilized eggs of White Leghorn chickens were purchased at a local hatchery and incubated at $37^{\circ} \mathrm{C}-38{ }^{\circ} \mathrm{C}$ with $60 \%$ relative humidity for 3 days. On day 5 , each egg was washed with warm $70 \%$ ethanol and opened a small window with $1.0 \mathrm{~cm}$ diameter on the sharp pole of the shell. We sealed the window by a $2 \times 2 \mathrm{~cm}$ medical fabric tape only on the edge of the opening, and the egg was allowed to continue the incubation. The following day, a 1-mm-thick sterile silicone ring with an inner diameter of $5 \mathrm{~mm}$ was laid on the exposed chorioallantoic membrane. We divided 54 well-incubated 6-day-old chicken embryos randomly into four groups, 12 eggs in each group, and six as blank controls. Both the nonintervened and cryopreserved MDA-MB-231 model tissues were adjusted to two concentrations: $4 \times 10^{6}$ and $8 \times 10^{6}$ cells/egg. Then the four groups of samples were grafted into pre-treated chicken embryos on the relative avascular region of CAM: group 1: $4 \times 10^{6}$ nonintervened cells; group 2: $8 \times 10^{6}$ non-intervened cells; group 3: $4 \times 10^{6}$ cryopreserved cells; group 4: $8 \times 10^{6}$ cryopreserved cells. The blank control grafted $40 \mu \mathrm{l}$ PBS. The five-millimeter inner diameter silicon rings were used to restrict the displacement of the grafts along with the chick embryo movement. The medical tape closed the window and continued to incubate for 6 days. The survival of the embryos, the tumor formation rate and the induction of angiogenesis were observed. The tumor with a diameter of $\geq 0.3 \mathrm{~cm}$ was considered positive, and the tumor formation rate was calculated. At the same time, the CAM xenograft specimens were fixed in situ with $4 \%$ paraformaldehyde and removed. The neovascularization in the tumor area was observed under a microscope on the 6th day of in vivo culture. The calculated field of blood vessels was set as the radial distribution within a radius of $1 \mathrm{~cm}$ from the grafted tissue. Image J software was applied to measure the area of vessels and CAM. The relative density of blood vessels was calculated by the formula: Vascular density = vasculature area/CAM area. Tumor volume was measured under an inverted microscope by the formula: Tumor volume $=1$ / $2 \times\left(\right.$ major axis $\times$ minor axis $\left.^{2}\right)$.

\section{Statistical analysis}

Data analysis was executed with SPSS 23.0 software (IBM Corp., Armonk, USA). The student's t-test was conducted to measure the differences between the cryopreserved and non-intervened groups. All statistical tests were 2 -sided. Data are expressed as mean \pm standard deviation (SD). The level of statistical significance was set at $p<0.05$. The $p$-values $<0.05,<0.01,<0.001$, and $<0.0001$ were represented by one, two, three, and four asterisks on the bars in the figures, respectively. At multiple time points, the group effects were tested using generalized linear mixed models to investigate the dynamic effects of cryopreservation on cell migration (wound healing assay).

\section{Results \\ Cell proliferation is invariable after cryopreservation}

After 5 days of in vitro culture, the ZR-75-1 cell concentration of the cryopreserved and non-intervened groups was $15.7 \times 10^{4}$ cells $/ \mathrm{ml}$ and $14.4 \times 10^{4}$ cells $/ \mathrm{ml}$, respectively, $p>0.05$. The MDA-MB-231 cell concentration of the cryopreserved and non-intervened groups was $25.1 \times 10^{4}$ cells $/ \mathrm{ml}$ and $26.6 \times 10^{4}$ cells $/ \mathrm{ml}$, respectively, $p>0.05$, respectively, showing no statistical significance.

\section{ZR-75-1 cells exhibit morphology change}

As shown in Fig. 1, a number of cryopreserved ZR-75-1 cells displayed morphology change from the typical grape-like cluster to fibroblast-like or spindle-shaped, and dissociated from the nearby cell cluster. The generation of filopodia and lamellipodia was observed. The compelling morphology changes are associated with the enhanced cell motility. Such cell characters were 


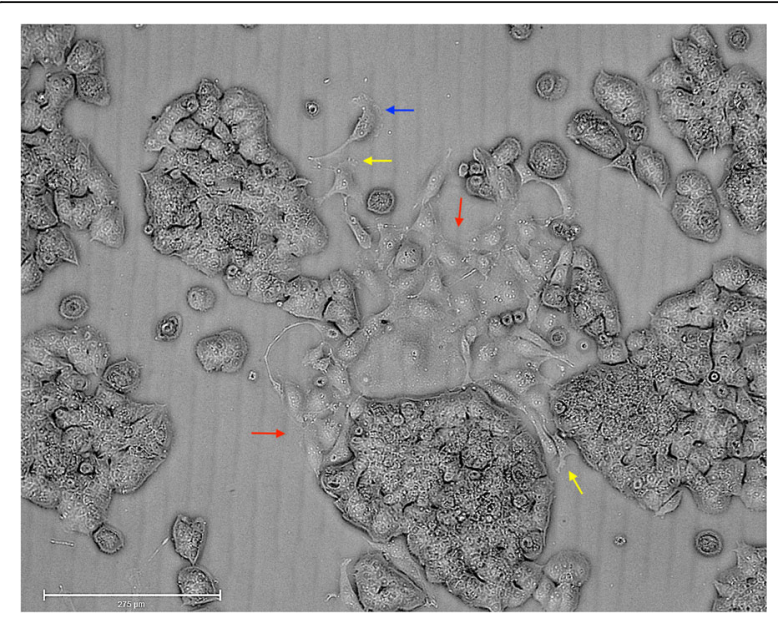

Fig. 1 Morphological change of ZR-75-1 cells after cryopreservation. After cryopreservation, the cells were in vitro cultured in a $10 \mathrm{~cm}$ Petri dish. The majority of ZR-75-1 cells stayed typical grape-like clusters. The red arrows pointed out the cells transformed into a spindle shape and dissociated from the nearby cell clusters. The blue and yellow arrows pointed out the generated lamellipodia and filopodia, respectively. Magnification $\times 150$

incapable to recognize in the cryopreserved MDA-MB231 cells under the microscope due to its primitive morphology.

\section{Cryopreservation increases migrating capability and invasion of the cancer cells}

Our data showed that the cancer cells after cryopreservation healed the wound area significantly more rapidly than before cryopreservation. For ZR-75-1 cells, the nonintervened group took over $72 \mathrm{~h}$ to close $100 \%$ of the gap, whereas the cryopreserved group healed the area within $72 \mathrm{~h}$. For MDA-MB-231 cells, the non-intervened group closed $35 \%$ of the gap in $6 \mathrm{~h}$, whereas the cryopreserved group covered $65 \%$ of the wound area, $p<0.05$.

By transwell assay, images of the stained cells on the bottom of the membrane were presented as photographic evidence of cell transmembrane migration and invasion. Data displayed that the cell dynamics and invasive capability were significantly enhanced in cancer cells after the cryopreservation treatment, as shown in Fig. 2. The number of migrated and invaded cells after $72 \mathrm{~h}$ (ZR-75-1) and $8 \mathrm{~h}$ (MDA-MB-231) culture was significantly higher in the cryopreserved group than the nonintervened group.

\section{Cryopreservation regulates the expression of protein $\mathrm{Ki}-$ 67 and P53}

Accordingly, the expression of multiple related proteins was the proxy assessment as evidence of the breast cancer cell phenotypes. By IF staining and WB, Ki-67 and P53 measurements were conducted in ZR-75-1 and
MDA-MB-231 cells. The proportion of Ki-67 positive cells decreased after cryopreservation, showing $50.7 \%$ vs. $45.0 \%, p>0.05$, in ZR-75-1 cells, and $82.6 \%$ vs. $79.6 \%$, $p>0.05$, in MDA-MB-231 cells. However, the expression of P53 slightly increased after cryopreservation, exhibiting no statistical difference compared to before cryopreservation, $p>0.05$.

\section{Cryopreservation induces loss of intercellular adhesion}

The expression of GATA3 and E-cadherin was investigated, which involved in intercellular adhesion formation. GATA3 expression reduced significantly in ZR-751 cells after cryopreservation compared to before the treatment. The MDA-MB-231 cell line was of triplenegative molecular subtype; thus, the GATA3 expression was incapable of capturing (Fig. 3).

E-cadherin expression was affected by GATA3. The immunofluorescent signals significantly attenuated in the cryopreserved cells, representing the protein downregulation (Fig. 4). Our data indicated that cryopreservation led to the loss of intercellular adhesion in breast cancer cells.

\section{Cryopreservation enhances cell motility by upregulating Vimentin and F-actin}

The IF images demonstrated that Vimentin and F-actin expression significantly upregulated in the cells after cryopreservation compared to those before cryopreservation. By WB, Vimentin expression was undetectable in the non-intervened ZR-75-1 cells, whereas it was captured high in the cryopreserved cells. The protein level in MDA-MB-231 cells further increased after cryopreservation compared to before the treatment (Fig. 5), suggesting enhanced cell dynamics.

\section{Cryopreservationn stimulates angiogenesis and tumor growth}

The survival rate of chick embryos inoculated by the non-intervened cells was $>90 \%$, and that of the two groups inoculated by cryopreserved cells was $>80 \%, p>$ 0.05 . The tumor formation rate was $>90 \%$ for the nonintervened and cryopreserved cancer cells, $p>0.05$.

In the blank samples, the disparity of the blood vessel morphology was not found between the inoculated and non-inoculated areas, presenting smooth and equably distributed. In groups 1, 2, 3, and 4, xenograft sites showed the radial distribution of blood vessels and an increased branching of the surrounding vasculature. Compared to the non-intervened group, it was observed in the cryopreserved groups a distinct growth of capillaries into the grafted tissue along with an increased number of peripheral blood vessels, which exhibited an intensive dendritic configuration (Fig. 6). The vascular area/ CAM area ratio of group 1, 2, 3, and 4 was $0.238 \pm$ 
A

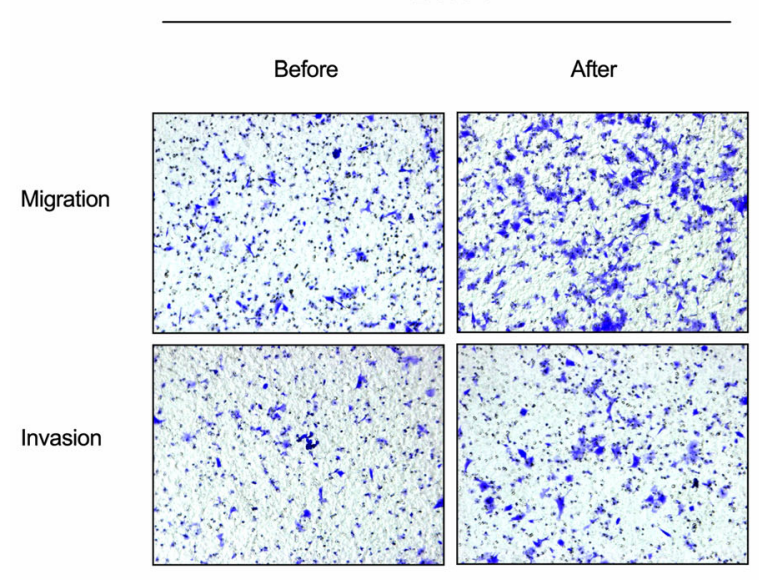

C

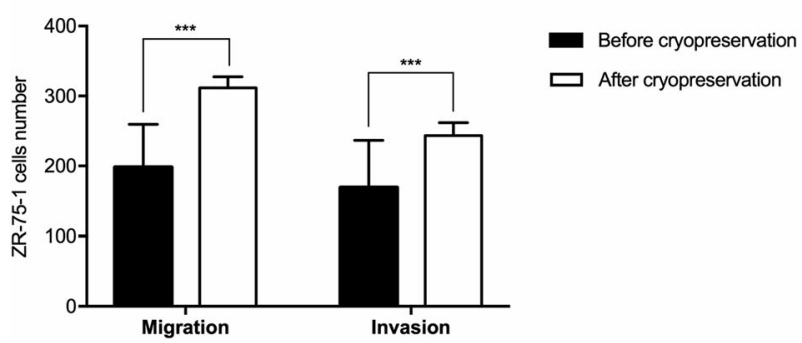

B

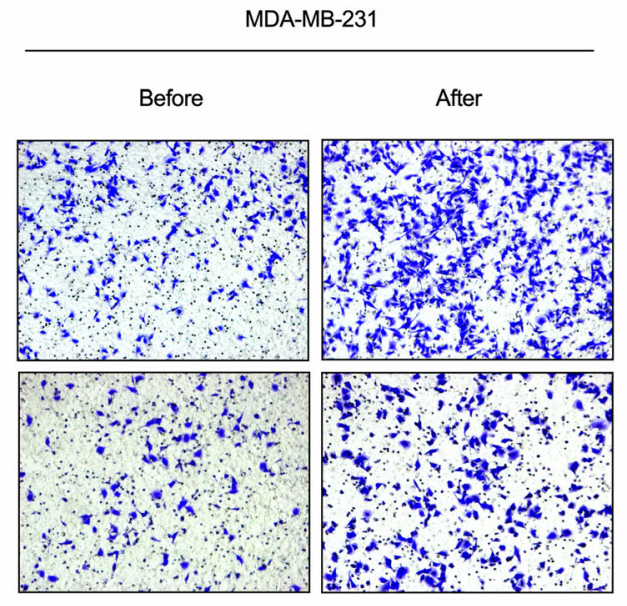

D

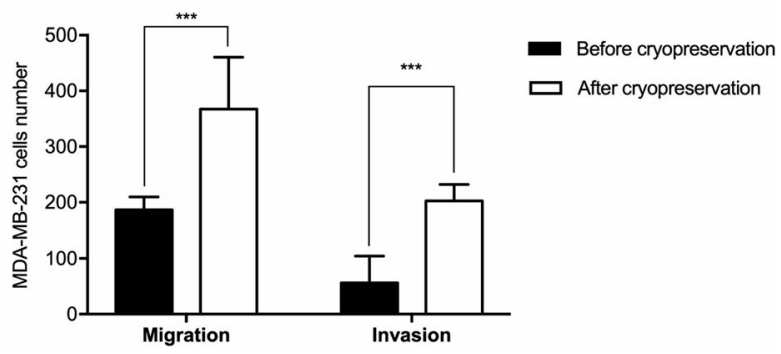

Fig. 2 Increased transmembrane migration and invasion of cryopreserved breast cancer cells. a ZR-75-1 cells of the non-intervened group/before cryopreservation and the investigated group/after cryopreservation were seeded in transwell and cultured for $72 \mathrm{~h}$. The number of stained cells on the bottom of the membrane after cryopreservation was significantly higher than before cryopreservation. $\mathbf{b}$ MDA-MB-231 cells of the group before and after cryopreservation were seeded in transwell and cultured for $8 \mathrm{~h}$. The number of stained cells on the bottom of the membrane after cryopreservation was significantly higher than before cryopreservation. $\mathbf{c}$ and $\mathbf{d}$ Triplicate samples of each group from three independent experiments were included $(n=3)$. Data are analyzed using Student's $t$-test, and expressed as mean \pm SD. Magnification $\times 13.5$. Significantly different at ${ }^{* * *} p<0.001$

$0.05,0.244 \pm 0.03,0.313 \pm 0.03$, and $0.342 \pm 0.04$, respectively. Thus, the vascular density of CAM transplanted by cryopreserved cells was higher, $p<0.0001$. The variances of group 1 vs. group 2 and group 3 vs. group 4 were not statistically significant.

The tumor volume in groups $1,2,3$, and 4 was $19.48 \pm 3.07 \mathrm{~mm}^{3}, \quad 22.61 \pm 6.99 \mathrm{~mm}^{3}, \quad 26.63 \pm 6.44 \mathrm{~mm}^{3}$, and $46.48 \pm 9.35 \mathrm{~mm}^{3}$, respectively. Tumor grafts in group 1 and group 2 were of small size, showing significant differences from those in group 3 and group $4, p<$ 0.05 . The grafts in group 4 were of high volume compared to the other three groups, $p<0.0001$, revealing that tumor growth was associated with the surrounded microenvironment and the autologous tumor burden.

\section{Discussion}

Ovarian tissue cryopreservation and the following transplantation have served as a fertility preservation approach for over a decade. More and more cancer survivors access this treatment for fertility restoration
$[17,18]$. The effect of cryopreservation on cell viability and genetic regulation has been thoroughly investigated on various cell types [19], while the impact on cancer cells is largely unknown. Our study is the first to characterize the phenotypes and molecular changes of breast cancer cell lines undergoing cryopreservation.

Here, we tested ZR-75-1 cells of luminal A and aggressive MDA-MB-231 cells of triple-negative molecular subtype. To prevent intracellular crystallization during the process of cryopreservation, we used permeable cryoprotectants to protect the cells. The main cryoprotectants are high molecular alcohols: glycerol, ethylene glycol, propylene glycol, and dimethyl sulfoxide (DMSO). The 'protective' component is usually 10 to $12 \%$ of the total solution and is either a single ingredient (DMSO) or a mixture of DMSO and the other one of the glycols [20]. In our protocol, we used a mixture of two cryoprotectants, which we used to protect ovarian fragments included at least five types of cells. Our data showed that the protective effect of $12 \%$ DMSO was 


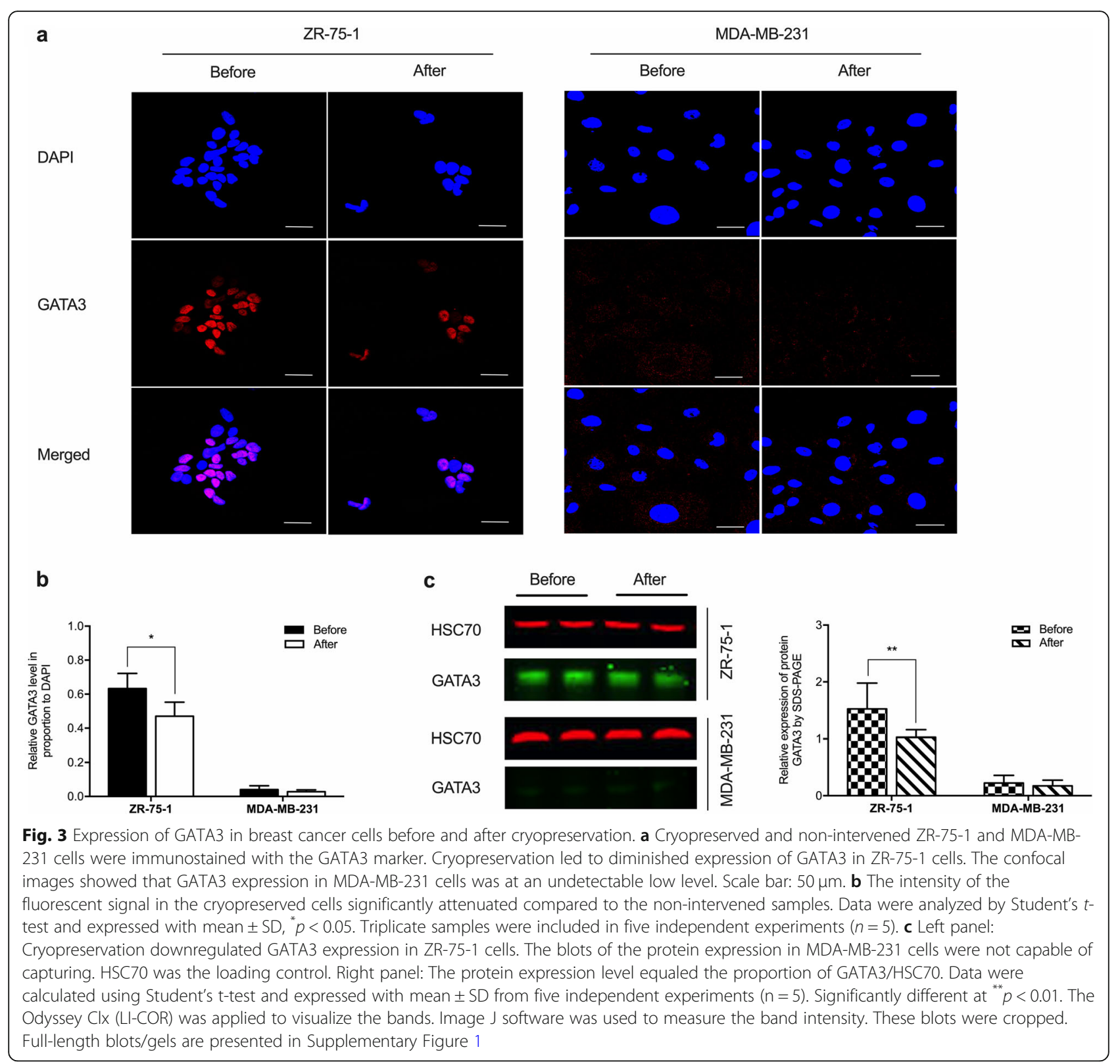

lower than that of a $12 \%$ multi-cryoprotectant solution (V. Isachenko, not published data). In this study, we further proved that cryopreservation using multicryoprotectants did not suppress cell growing ability reflected in the expression of Ki-67 and P53 in the cryopreserved and non-intervened breast cancer cells.

Epithelial-to-mesenchymal transition (EMT) is a reversible process, during which epithelial cells lose intercellular adherence and gain migratory and invasive properties to transdifferentiate to mesenchymal cells. We observed the decreased expression of GATA3 and E-cadherin in the cryopreserved cells. GATA3 functions as a critical transcriptional activator of E-cadherin to impede the phenotype transition between epithelial and mesenchymal cells, and suppresses metastasis and alters the tumor microenvironment in breast cancer [21]. Ecadherin is responsible for cell-cell adhesion. Wild-type Ecadherin downregulation is related to the reduction of intercellular adhesion [22]. Loss of E-cadherin is considered to be an elemental event in the process of EMT, which played a vital role in cancer metastasis [23]. It was reported that the expression of E-cadherin was suppressed in GATA3-knockout MDA-MB-231 cells [24]. Our data illustrated that the expression level of E-cadherin in ZR75-1 cells was correlated to that of GATA3.

Vimentin and actin form the intermediate filament and microfilament, respectively, and participate in cell motility. Vimentin is the major cytoskeletal component 


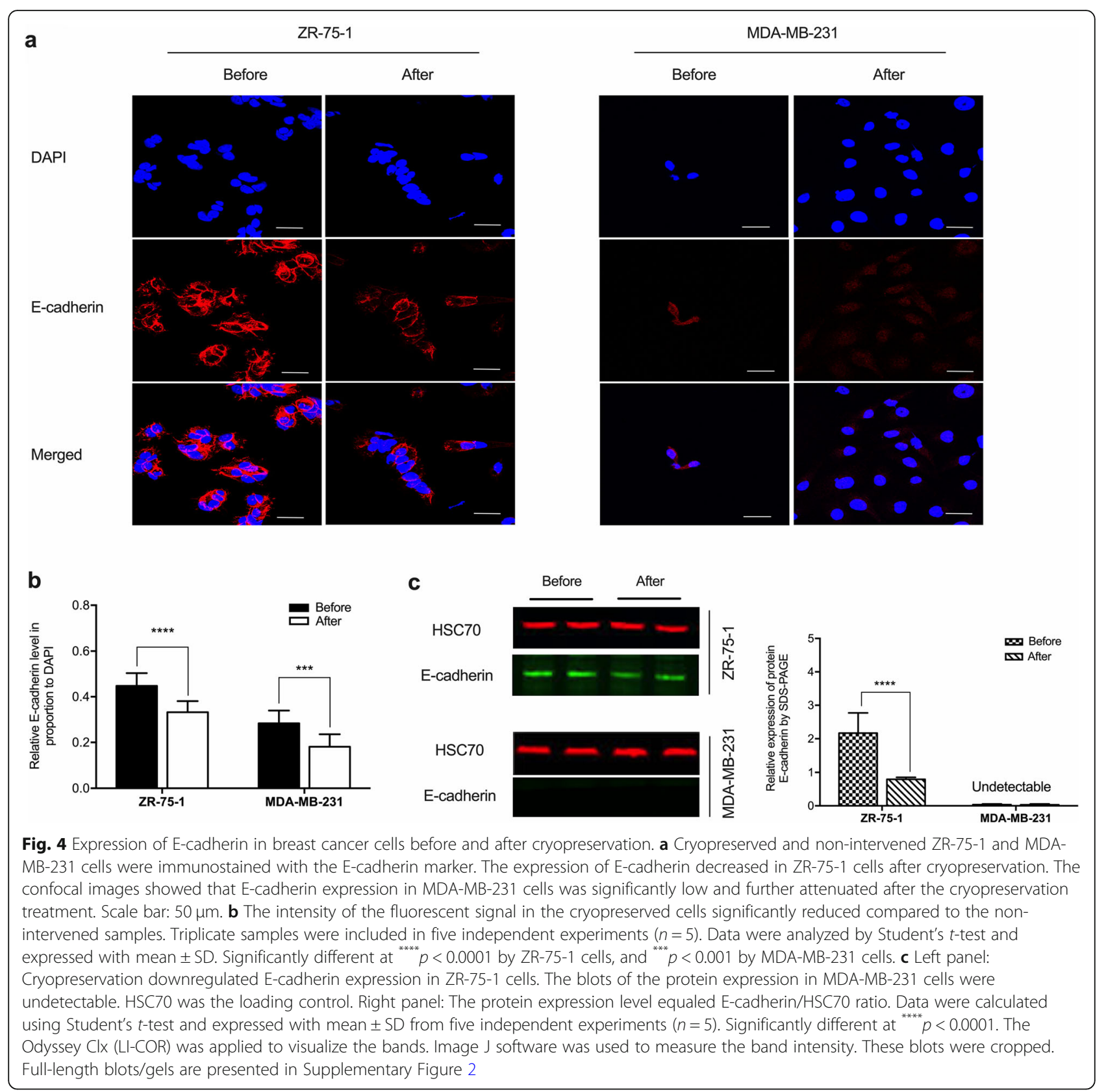

of mesenchymal cells. F-actin also engages in the maintenance of cell shape. Since the induction of cell motility is considered the second phase of EMT [25, 26], we evaluated these two cytoskeletal proteins to reveal the mechanism of the enhanced cell moving after cryopreservation. Our data indicated that cryopreservation induced the improved migrating capability and invasion in breast cancer cells by upregulating the expression of Vimentin and F-actin and reorganizing intermediate filaments and microfilaments.

Angiogenesis is a vital process for tumor growth and spread. Our results revealed that cryopreserved breast cancer cells stimulated the generation of neovasculature.
Subsequently, the cryopreserved grafts were of large volume after acquiring the newly established blood supply.

There are adverse effects observed at somatic cells cryopreservation: hypoxia is one of the most substantial effects besides intracellular $\mathrm{Ca}^{2+}$ concentration, osmotic disruption of cellular membranes, generation of reactive oxygen species, and lipid peroxidation [27]. Cryopreserved cancer cells experience an imbalance between oxygen delivery and consumption through the procedures of freezing and thawing. The condition of low oxygen tension activates the hypoxia-inducible factors (HIFs), increases the permeability of the mitochondrial 


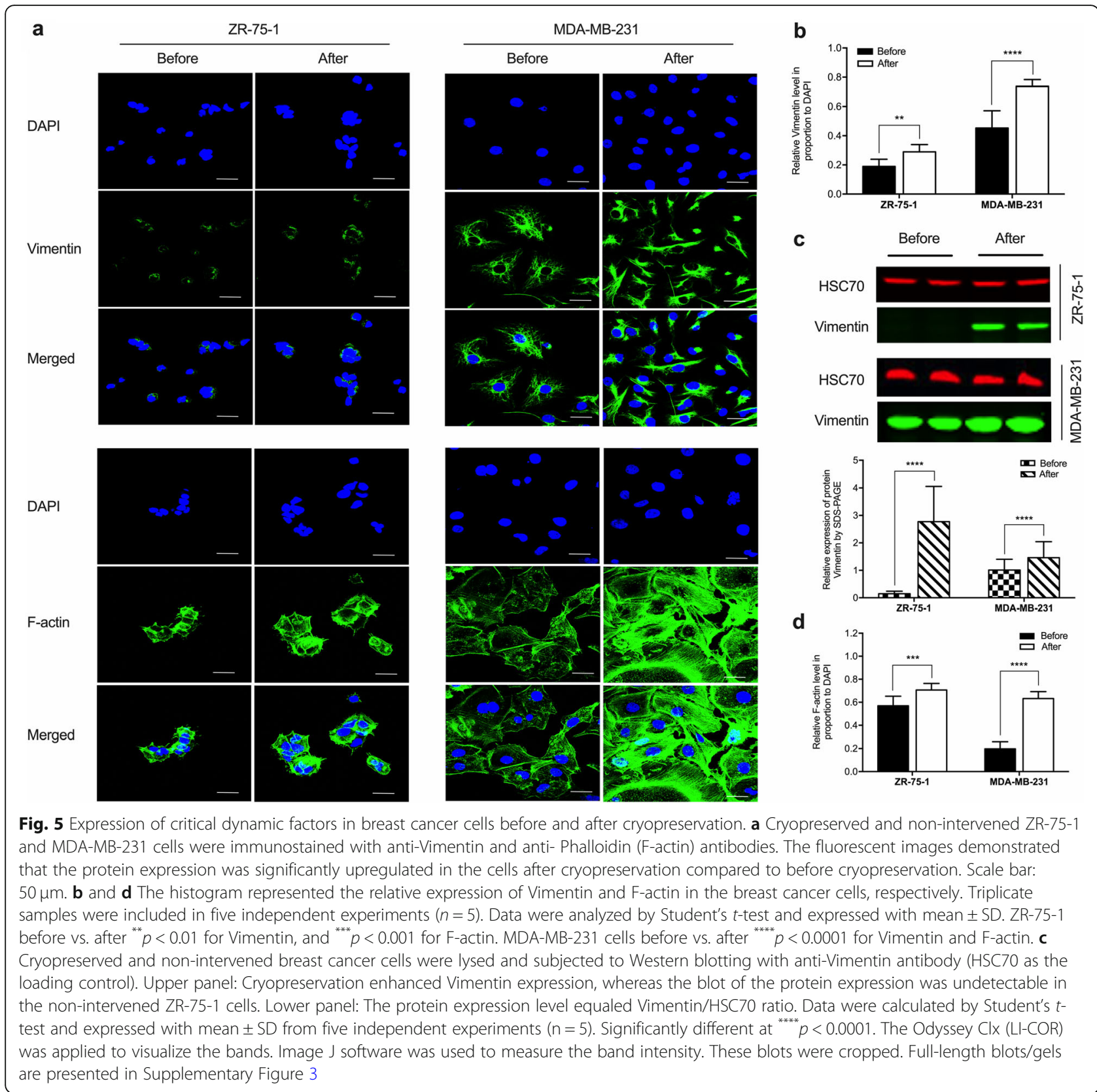

membrane, causes mitochondrial swelling [28, 29], and enhances malignant phenotypes of cancer cells, that are positively correlated to cancer metastasis [30]. The transcription factors HIFs mediate the primary responses to hypoxia $[31,32]$. Thereby, we inferred that cryopreservation altered GATA3 and E-cadherin expression through the activation of HIFs. HIFs also induce proteinases involved in the degradation of the extracellular matrix to accelerate the invasion then affect cell motility corresponding to cell migration and invasion, which is the first step of metastasis cascade [31].

Cell migration is associated with the metabolism of cellular energy. By cryopreservation, HIFs activation and mitochondria swelling increase glycolysis and thus sustain cancer metastasis [33-35]. Calcium regulates focal adhesion turnover, cytoskeletal reorganization, and other tumor cell movement processes through contact with multiple downstream proteins [36]. Whether HIFs and mitochondria induce the upregulation of Vimentin and F-actin still needs further research.

Tumors induce neovascularization by secreting various growth factors and proteinases $[37,38]$, several of which are the downstream proteins induced by HIFs. Besides, cancer cells cease mitosis and survive in dormancy under the condition of low temperature. A stable microvasculature constitutes dormant niches of cancer cells 

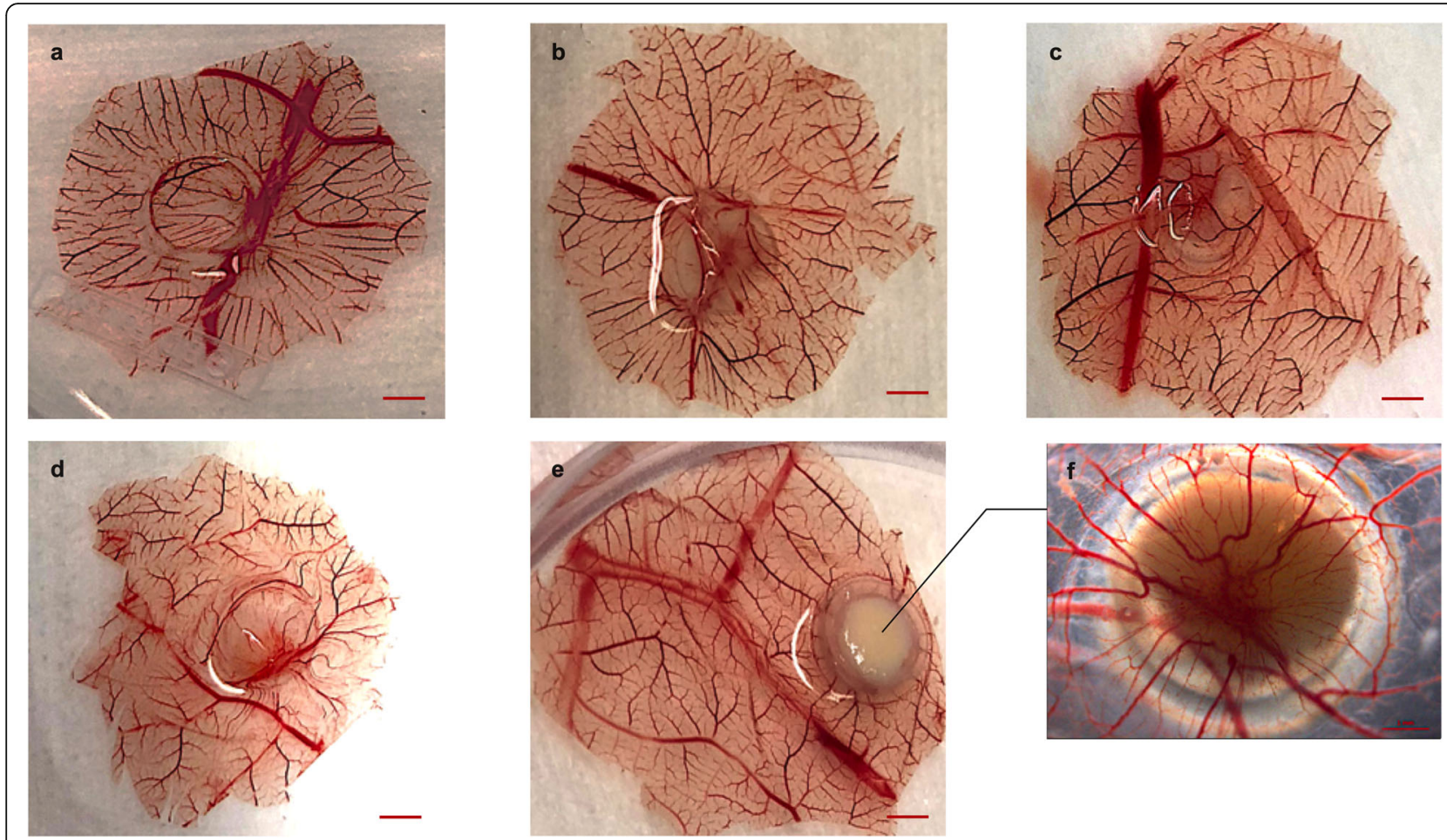

Fig. 6 Angiogenesis on the CAM induced by MDA-MB-231 cells. The non-intervened cancer cells and the cells after cryopreservation were accumulated and transplanted on the relative avascular region of the CAM. a Negative control: $40 \mu \mathrm{l} 1 \mathrm{X}$ Phosphate-Buffered Saline. $\mathbf{b}$ Representative sample of group 1: $4 \times 10^{6}$ non-intervened cells. c Representative sample of group 2: $8 \times 10^{6}$ non-intervened cells. $\mathbf{d}$ Representative sample of group 3: $4 \times 10^{6}$ cryopreserved cells. e Representative sample of group 4: $8 \times 10^{6}$ cryopreserved cells; Scale bar: $2.5 \mathrm{~mm}$. f The reverse side of sample in (e). It was detected numerous radically distributed vasculature and vertically growth into the tissues, which was indicated by the reddishness at the middle of the transplanted sites. Scale bar: $1 \mathrm{~mm}$. Image J software was applied to measure the area of vessels and CAM

[39]. Angiogenesis accelerates the growth of quiescent breast cancer cells [40].

\section{Conclusions}

Cryopreservation promotes breast cancer cells in terms of epithelial-mesenchymal transition and angiogenesis induction, thus increasing metastasis risk.

\section{Supplementary information}

Supplementary information accompanies this paper at https://doi.org/10. 1186/s12885-020-07227-z.

\footnotetext{
Additional file 1: Figure S1. The uncropped full-length western blotting images of Fig. 3. a The original blots/gels of the ZR-75-1 cell line. $\mathbf{b}$ The original blots/gels of the MDA-MB-231 cell line. Each image included four proteins, i.e., P53, E-cadherin, GATA3, and Vimentin, with 53kd, $125 \mathrm{kd}, 48 \mathrm{kd}$, and $53 \mathrm{kd}$ of the expected molecular weight, respectively. HSC70 was used as the loading control. The first column on the left was the standard protein ladder. The molecular weights were labeled aside. Measurement of each protein marker occupied four adjacent tracks, of which the two on the left and the two on the right represented the expression of the relevant protein in the cell samples before and after cryopreservation, respectively. The white frames highlighted the green blots
}

of GATA3 and red blots of HSC70, as shown in Fig. 3. Bands were visualized using the Odyssey Clx (LI-COR).

Additional file 2: Figure S2. The uncropped full-length western blotting images of Fig. 4. a The original blots/gels of the ZR-75-1 cell line. $\mathbf{b}$ The original blots/gels of the MDA-MB-231 cell line. Each image included four proteins, i.e., P53, E-cadherin, GATA3, and Vimentin, with 53kd,

$125 \mathrm{kd}, 48 \mathrm{kd}$, and $53 \mathrm{kd}$ of the expected molecular weight, respectively. HSC70 was used as the loading control. The first column on the left was the standard protein ladder. The molecular weights were labeled aside. Measurement of each protein marker occupied four adjacent tracks, of which the two on the left and the two on the right represented the expression of the relevant protein in the cell samples before and after cryopreservation, respectively. The white frames highlighted the green blots of E-cadherin and red blots of HSC70, as shown in Fig. 4. Bands were visualized using the Odyssey Clx (LI-COR)

Additional file 3: Figure $\mathbf{S 3}$ The uncropped full-length western blotting images of Fig. 5. a The original blots/gels of the ZR-75-1 cell line. $\mathbf{b}$ The original blots/gels of the MDA-MB-231 cell line. Each image included four proteins, i.e., P53, E-cadherin, GATA3, and Vimentin, with 53kd, 125kd, $48 \mathrm{kd}$, and $53 \mathrm{kd}$ of the expected molecular weight, respectively. HSC70 was used as the loading control. The first column on the left was the standard protein ladder. The molecular weights were labeled aside. Measurement of each protein marker occupied four adjacent tracks, of which the two on the left and the two on the right represented the expression of the relevant protein in the cell samples before and after cryopreservation, respectively. The white frames highlighted the green blots of 
Vimentin and red blots of HSC70, as shown in Fig. 5. Bands were visualized using the Odyssey Clx (LI-COR).

\section{Abbreviations}

OTC: Ovarian tissue cryopreservation; UCB-MNCs: Umbilical cord blood mononuclear cells; FBS: Fetal bovine serum; CCK-8: Cell counting kit-8; IF: Immunofluorescent; E-cadherin: Epithelial cadherin; WB: Western blotting; CAM: Chorioallantoic membrane; SDS-PAGE: Sodium dodecyl sulfatepolyacrylamide gel electrophoresis; SD: Standard deviation; DMSO: Dimethyl sulfoxide; EMT: Epithelial-to-mesenchymal transition; HIFs: Hypoxia-inducible factors

\section{Acknowledgements}

We want to thank Prof. Bjoern Schumacher and Dr. Siyao Wang for their expert technical guidance and assistance. We would like to thank Ms. Mengying Wang for excellent assistance for data collection.

\section{Authors' contributions}

$X D, E I$, and $\mathrm{VI}$ contributed to the conceptualization, methodology, and investigation. XD and PT performed data analysis and wrote the manuscript. GR, PM, and YM wrote review and editing. VI contributed to supervision and project administration. All authors read and approved the final manuscript.

\section{Funding}

This project was supported by the grant from China Scholarship Council (No. 201508110223) to Xinxin Du. The funding bodies were not involved in the study design, data collection, data analysis, and interpretation, or the writing and submitting of this manuscript for publication. Open access funding provided by Projekt DEAL.

\section{Availability of data and materials}

The datasets used and/or analyzed during the current study are available from the corresponding author on reasonable request.

\section{Ethics approval and consent to participate}

It is confirmed that any of the cell lines used in this research do not require ethics approval.

\section{Consent for publication}

Not applicable.

\section{Competing interests}

The authors declare that they have no competing of interest.

\section{Author details}

${ }^{1}$ Research Group for Reproductive Medicine, IVF-Laboratory and Department of Gynecology, University of Cologne, Kerpener str. 34, 50931 Cologne, NRW, Germany. ${ }^{2}$ Department of Obstetrics and Gynecology, PLA General Hospital, Beijing, China. ${ }^{3}$ Institute of Biology and Immunology of Reproduction, Bulgarian Academy of Sciences, Sofia, Bulgaria.

Received: 2 May 2020 Accepted: 28 July 2020

Published online: 12 August 2020

\section{References}

1. Macklon KT. Prevalence of deaths in a cohort of girls and women with cryopreserved ovarian tissue. Acta Obstet Gynecol Scand. 2019.

2. Poirot C, Brugieres L, Yakouben K, Prades-Borio M, Marzouk F, de Lambert $G$ Pacquement H, Bernaudin F, Neven B, Paye-Jaouen A, et al. Ovarian tissue cryopreservation for fertility preservation in 418 girls and adolescents up to 15 years of age facing highly gonadotoxic treatment. Twenty years of experience at a single center. Acta Obstet Gynecol Scand. 2019;98(5):630.

3. Paez D, Labonte MJ, Bohanes P, Zhang W, Benhanim L, Ning Y, Wakatsuki T, Loupakis F, Lenz HJ. Cancer dormancy: a model of early dissemination and late cancer recurrence. Clin Cancer Res. 2012;18(3):645-53.

4. Bochev I, Belemezova K, Shterev A, Kyurkchiev S. Effect of cryopreservation on the properties of human endometrial stromal cells used in embryo coculture systems. J Assist Reprod Genet. 2016;33(4):473-80.

5. Hengstler JG, Utesch D, Steinberg P, Platt K, Diener B, Ringel M, Swales N, Fischer T, Biefang K, Gerl M. Cryopreserved primary hepatocytes as a constantly available in vitro model for the evaluation of human and animal drug metabolism and enzyme induction. Drug Metab Rev. 2000;32(1):81118.

6. Lin RZ, Dreyzin A, Aamodt K, Dudley AC, Melero-Martin JM. Functional endothelial progenitor cells from cryopreserved umbilical cord blood. Cell Transplant. 2011;20(4):515-22.

7. Yin Y, Liu H, Wang F, Li L, Deng M, Huang L, Zhao X. Transplantation of cryopreserved human umbilical cord blood-derived endothelial progenitor cells induces recovery of carotid artery injury in nude rats. Stem Cell Res Ther. 2015;6:37.

8. Berkovitz A, Miller N, Silberman M, Belenky M, Itsykson P. A novel solution for freezing small numbers of spermatozoa using a sperm vitrification device. Human Reprod (Oxford, England). 2018;33(11):1975-83.

9. Gallardo M, Paulini F, Corral A, Balcerzyk M, Lucci CM, Ambroise J, Merola M, Fernandez-Maza L, Risco R, Dolmans MM, et al. Evaluation of a new freezing protocol containing 20\% dimethyl sulphoxide concentration to cryopreserve human ovarian tissue. Reprod BioMed Online. 2018:37(6):65365.

10. Le MT, Nguyen TT, Nguyen TT, Nguyen VT, Nguyen TTA, Nguyen VQH, Cao NT. Cryopreservation of human spermatozoa by vitrification versus conventional rapid freezing: effects on motility, viability, morphology and cellular defects. Eur J Obstet Gynecol Reprod Biol. 2019;234:14-20.

11. Aguirre-Ghiso JA. Models, mechanisms and clinical evidence for cancer dormancy. Nat Rev Cancer. 2007;7(11):834-46.

12. Du X, Klaschik K, Mallmann P, Isachenko E, Rahimi G, Zhao Y, Bruns C, Isachenko V. An experimental model of breast Cancer cells: informative protocol for in vitro culture. Anticancer Res. 2018;38(11):6237-45.

13. Isachenko V, Todorov P, Isachenko E, Rahimi G, Hanstein B, Salama M, Mallmann P, Tchorbanov A, Hardiman P, Getreu N, et al. Cryopreservation and xenografting of human ovarian fragments: medulla decreases the phosphatidylserine translocation rate. Reprod Biol Endocrinol. 2016;14(1):79.

14. Isachenko V, Montag M, Isachenko E, van der Ven $\mathrm{K}$, Dorn C, Roesing B, Braun F, Sadek F, van der Ven $\mathrm{H}$. Effective method for in-vitro culture of cryopreserved human ovarian tissue. Reprod BioMed Online. 2006;13(2):228-34.

15. Isachenko V, Mallmann P, Petrunkina AM, Rahimi G, Nawroth F, Hancke K, Felberbaum R, Genze F, Damjanoski I, Isachenko E. Comparison of in vitroand Chorioallantoic membrane (CAM)-culture Systems for Cryopreserved Medulla-Contained Human Ovarian Tissue. PLoS One. 2012;7(3):9.

16. Zeng YC, Tang HR, Zeng LP, Chen Y, Wang GP, Wu RF. Assessment of the effect of different vitrification solutions on human ovarian tissue after shortterm xenotransplantation onto the chick embryo chorioallantoic membrane. Mol Reprod Dev. 2016;83(4):359-69.

17. Fabbri R, Macciocca M, Vicenti R, Paradisi R, Rossi S, Sabattini E, Gazzola A, Seracchioli R. First Italian birth after cryopreserved ovarian tissue transplantation in a patient affected by non-Hodgkin's lymphoma. Int J Hematol Oncol. 2018;7(4):ljh08.

18. Ruan X, Du J, Korell M, Kong W, Lu D, Jin F, Li Y, Dai Y, Yin C, Yan S, et al. Case report of the first successful cryopreserved ovarian tissue retransplantation in China. Climacteric. 2018;21(6):613-6.

19. Pogozhykh D, Pogozhykh O, Prokopyuk V, Kuleshova L, Goltsev A, Blasczyk $\mathrm{R}$, Mueller T. Influence of temperature fluctuations during cryopreservation on vital parameters, differentiation potential, and transgene expression of placental multipotent stromal cells. Stem Cell Res Ther. 2017:8(1):66.

20. Gook DA, Edgar DH. Ovarian tissue cryopreservation. In: Donnez J, Kim SS, editors. Principles and practice of fertility preservation, vol. 2. New York: Cambridge University Press; 2011. p. 342-56.

21. Chou J, Lin JH, Brenot A, Kim JW, Provot S, Werb Z. GATA3 suppresses metastasis and modulates the tumour microenvironment by regulating microRNA-29b expression. Nat Cell Biol. 2013;15(2):201-13.

22. Rosso M, Lapyckyj L, Besso MJ, Monge M, Reventos J, Canals F, Quevedo Cuenca JO, Matos ML, Vazquez-Levin MH. Characterization of the molecular changes associated with the overexpression of a novel epithelial cadherin splice variant mRNA in a breast cancer model using proteomics and bioinformatics approaches: identification of changes in cell metabolism and an increased expression of lactate dehydrogenase B. Cancer Metab. 2019;7:5.

23. Yang J, Weinberg RA. Epithelial-mesenchymal transition: at the crossroads of development and tumor metastasis. Dev Cell. 2008:14(6):818-29.

24. Kim KS, Kim J, Oh N, Kim MY, Park KS. ELK3-GATA3 axis modulates MDA-MB231 metastasis by regulating cell-cell adhesion-related genes. Biochem Biophys Res Commun. 2018;498(3):509-15. 
25. Chen Y, Chen ZY, Chen L, Zhang JY, Fu LY, Tao L, Zhang Y, Hu XX, Shen XC. Shikonin inhibits triple-negative breast cancer-cell metastasis by reversing the epithelial-to-mesenchymal transition via glycogen synthase kinase 3beta-regulated suppression of beta-catenin signaling. Biochem Pharmacol. 2019;166:33-45.

26. Avtanski D, Garcia A, Caraballo B, Thangeswaran P, Marin S, Bianco J, Lavi A, Poretsky L. Resistin induces breast cancer cells epithelial to mesenchymal transition (EMT) and stemness through both adenylyl cyclase-associated protein 1 (CAP1)-dependent and CAP1-independent mechanisms. Cytokine. 2019;120:155-64

27. Isachenko V, Todorov P, Isachenko E, Rahimi G, Tchorbanov A, Mihaylova N, Manoylov I, Mallmann P, Merzenich M. Long-time cooling before cryopreservation decreased translocation of Phosphatidylserine (Ptd-L-Ser) in human ovarian tissue. PLoS One. 2015;10(6):e0129108.

28. Hussain S. Measurement of Nanoparticle-Induced Mitochondrial Membrane Potential Alterations. Methods Mol Biol (Clifton, NJ). 2019;1894:123-31.

29. Makarov VI, Khmelinskii I, Javadov S. Computational Modeling of In Vitro Swelling of Mitochondria: A Biophysical Approach. Molecules. 2018;23:4.

30. Hiraga T. Hypoxic Microenvironment and Metastatic Bone Disease. Int J Mol Sci. 2018:19:11.

31. Schito L, Semenza GL. Hypoxia-inducible factors: master regulators of Cancer progression. Trends Cancer. 2016;2(12):758-70.

32. Rankin EB, Nam JM, Giaccia AJ. Hypoxia: signaling the metastatic Cascade. Trends Cancer. 2016;2(6):295-304.

33. Abd El-Hafez YG, Moustafa HM, Khalil HF, Liao CT, Yen TC. Total lesion glycolysis: a possible new prognostic parameter in oral cavity squamous cell carcinoma. Oral Oncol. 2013;49(3):261-8.

34. Zhao T, Zhu Y, Morinibu A, Kobayashi M, Shinomiya K, Itasaka S, Yoshimura M, Guo G, Hiraoka M, Harada H. HIF-1-mediated metabolic reprogramming reduces ROS levels and facilitates the metastatic colonization of cancers in lungs. Sci Rep. 2014;4:3793.

35. Zhang Y, Fang N, You J, Zhou Q. Advances in the relationship between tumor cell metabolism and tumor metastasis. Zhongguo Fei Ai Za Zhi. 2014;17(11):812-8.

36. Di J, Huang H, Qu D, Tang J, Cao W, Lu Z, Cheng Q, Yang J, Bai J, Zhang Y, et al. Rap2B promotes proliferation, migration, and invasion of human breast cancer through calcium-related ERK1/2 signaling pathway. Sci Rep. 2015;5:12363.

37. Zhou R, Wang S, Wen H, Wang M, Wu M. The bispecific antibody HB-32, blockade of both VEGF and DLL4 shows potent anti-angiogenic activity in vitro and anti-tumor activity in breast cancer xenograft models. Exp Cell Res. 2019;380(2):141-8.

38. Thammineni KL, Thakur GK, Kaur N, Banerjee BD. Significance of MMP-9 and VEGF-C expression in north Indian women with breast cancer diagnosis. Mol Cell Biochem. 2019.

39. Endo H, Inoue M. Dormancy in cancer. Cancer Sci. 2019:110(2):474-80.

40. Ghajar CM, Peinado H, Mori H, Matei IR, Evason K, Brazier H, Almeida D, Koller A, Hajjar KA, Stainier DY, et al. The perivascular niche regulates breast tumour dormancy. Nat Cell Biol. 2013;15(7):807-17.

\section{Publisher's Note}

Springer Nature remains neutral with regard to jurisdictional claims in published maps and institutional affiliations.

Ready to submit your research? Choose BMC and benefit from:

- fast, convenient online submission

- thorough peer review by experienced researchers in your field

- rapid publication on acceptance

- support for research data, including large and complex data types

- gold Open Access which fosters wider collaboration and increased citations

- maximum visibility for your research: over $100 \mathrm{M}$ website views per year

At BMC, research is always in progress.

Learn more biomedcentral.com/submissions 